\title{
ORIGINAL
}

\section{Effects of very short rest periods on testosterone to cortisol ratio during heavy resistance exercise in men}

\author{
Rahman Rahimi $^{\text {a,* }}$, Hadi Rohani ${ }^{\mathrm{b}}$, Mohsen Ebrahimi ${ }^{\mathrm{c}}$ \\ a Department of Physical Education and Sport Science, University of Kurdistan, Sanandaj, Iran \\ ${ }^{\mathrm{b}}$ Faculty of Physical Education and Sport Science, University of Guilan, Rasht, Iran \\ c Department of Physical Education and Sport Science, University of Semnan, Iran
}

Received 5 February 2011; accepted 28 March 2011

Available online 18 May 2011

\section{KEYWORDS}

Resistance exercise; Rest interval between set;

Testosterone to cortisol ratio

\section{PALABRAS CLAVE \\ Ejercicio de resistencia; Intervalo de reposo entre series; Relación de testosterona y cortisol}

\begin{abstract}
The ratio between testosterone and cortisol concentration (Ts/Co ratio) is frequently used as an index of the stress level in exercise training. Changes in this ratio are responsible for several training responses such as hypertrophy and strength gain. So the purpose of this study was to investigate the effect of 4 sets of bench press and squat to failure with $\% 85$ of 1 RM using different rest intervals of 60 (P60), 90 (P90) and 120 (P120) second on testosterone to cortisol ratio in resistance trained men. Ten recreationally resistance-trained men (age, $22 \pm 2$ years; weight, $84 \pm 8 \mathrm{~kg}$; height, $178.5 \pm 8.5$; at least 1 year of resistance exercise [RE] experience) performed RE protocols on randomized separating session. Blood draws occurred at pre-exercise (Pre); immediately after (Post) and 30 min after the end of the session (30Post) for measurement serum testosterone and cortisol concentrations. The results of this study indicated that Ts/Co ratio in P60 trail was significantly lower at post and 30 min post compare to pre-exercise $(p \leq 0.05)$. The Ts/Co ratio at post exercise was significantly higher in $\mathrm{P} 120$ than $\mathrm{P} 60$ and $\mathrm{P} 90(\mathrm{P} \leq 0.05)$, but no difference was found between P60 and P90. The data indicate that long rest period between sets in RE to failure resulted in a grater increase in Ts/Co ratio than short rest period between sets in RE. The enhanced in Ts/Co ratio by long rest period between sets, indicating an augmented anabolic state to RE in resistance trained men. (c) 2011 Consell Català de l'Esport. Generalitat de Catalunya. Published by Elsevier España, S.L. All rights reserved.
\end{abstract}

Efectos de los períodos de reposo muy cortos en la relación de testosterona y cortisol durante ejercicios de alta resistencia en hombres

Resumen La relación entre la concentración de testosterona y cortisol (relación T/C) se suele utilizar como índice del nivel de esfuerzo en la práctica de ejercicio físico. Los cambios que se producen en esta relación son los responsables de varias reacciones al ejercicio, como la hipertrofia y el aumento de fuerza. Así, el objetivo de este estudio fue explorar el efecto de 4 series de press banca y sentadillas hasta el fallo con $85 \%$ de 1 RM utilizando diferentes intervalos de reposo de 60 (P60), 90 (P90) y 120 (P120) segundos sobre la relación de testosterona y cortisol

\footnotetext{
* Corresponding author.

E-mail address: rahman.rahimi@yahoo.com (R. Rahimi).
} 
en hombres entrenados en ejercicios de resistencia. Diez hombres entrenados en ejercicios de resistencia por placer (edad: $22 \pm 2$ años; peso: $84 \pm 8 \mathrm{~kg}$; altura: $178,5 \pm 8,5$; con 1 año de experiencia como mínimo en ejercicios de resistencia [ER]) realizaron protocolos de ER en sesiones aleatorias por separado. Se extrajeron muestras de sangre antes del ejercicio (pre), inmediatamente después (post) y 30 min después del fin de la sesión (30-post) para analizar las concentraciones séricas de testosterona y cortisol. Los resultados de este estudio indicaron que la relación T/C en el intervalo P60 fue significativamente más baja en post y 30-post en comparación con la previa al ejercicio $(\mathrm{p} \leq 0,05)$. La relación $\mathrm{T} / \mathrm{C}$ después del ejercicio fue significativamente más alta en $\mathrm{P} 120$ que en $\mathrm{P} 60$ y $\mathrm{P} 90(\mathrm{p} \leq 0,05)$, pero no se observaron diferencias entre P60 y P90. Los datos indican que el período de reposo largo entre series en ER hasta el fallo obtuvo un aumento mayor de la relación T/C que el período de reposo corto. La mejora de la relación T/C mediante períodos de reposo largos entre series indica un aumento del estado anabólico hasta el ER en hombres entrenados en ejercicios de resistencia.

(c) 2011 Consell Català de l'Esport. Generalitat de Catalunya. Publicado por Elsevier España, S.L. Todos los derechos reservados.

\section{Introduction}

There are many studies about optimizing resistance training. Some factors investigated in these studies are volume, intensity, rest period between sets and exercise order. ${ }^{1-4}$ It appears that manipulation of these training variables can influence hormonal and biological responses to training and then training results. ${ }^{4,5}$

The ratio between the concentration of testosterone and cortisol (Ts/Co ratio) is frequently used as an index of the stress level in exercise training. Changes in this ratio are responsible for several training responses such as hypertrophy and strength gain. ${ }^{6,7}$ Furthermore, there is some evidence suggest that the Ts/Co ratio would be a physiological indicator of overtraining in heavy load exercise training, but it is not enough for prediction of overtraining syndromes. ${ }^{5,8,9}$

Previous studies have indicated that Ts and Co responses to resistance exercise are affected by several variables such as intensity, volume, duration, rest periods, and muscle mass involvement. ${ }^{10,11}$

It is demonstrated that rest interval period between sets would be an important factor that can be manipulated and effects on work performed in subsequent sets, ${ }^{12,13}$ the metabolic $^{14}$ and hormonal ${ }^{15-17}$ responses to exercise training, and training adaptations. ${ }^{18-20}$ However, acute response of $\mathrm{Co}$ and Ts to different rest interval is not well known. Bottaro et $\mathrm{al}^{15}$ found that there are no differences in acute response of Co to a resistance exercise protocol with 30 , 60 and 120 second (s) rest interval between sets in trained women. Also, Ahtiainen et $\mathrm{al}^{21}$ observed no significant differences in acute effect of short ( $2 \mathrm{~min}$ ) and long $(5 \mathrm{~min})$ rest interval on concentrations of serum total Ts, free Ts, and Co. But, recently Rahimi et $\mathrm{al}^{3}$ have demonstrated that serum Ts concentrations were significantly higher in 120 and $90 \mathrm{~s}$ of rest interval between sets compared to $60 \mathrm{~s}$ in men. Interestingly, Buresh et $\mathrm{al}^{16}$ showed that concentration of both Co and Ts with short rest interval $(1 \mathrm{~min})$ was more than long rest interval $(2.5 \mathrm{~min})$ after 1 week resistance training in untrained men. Since, Ts/Co ratio is an important indicative of anabolic and catabolic status, it is important to know how the resistance-trained men respond to stress imposed by different rest interval between sets in resistance exercise. However, to date no studies have compared the acute effects of different rest intervals between resistance exercise sets' on Ts/Co ratio. Therefore, the purpose of this study was to determine the effect of different rest intervals of 60,90 , and 120 s between sets during a resistance exercise protocol on Ts to Co ratio in resistance trained men.

\section{Methods}

\section{The experimental approach to the problem}

The primary research hypothesis of this investigation was that different rest intervals between sets would improve Ts/Co ratio. Each subject participated in 3 testing sessions, randomized and counterbalanced, involving 4 sets bench press and squat at $85 \%$ of $1 \mathrm{RM}$ to failure with 60,90 and $120 \mathrm{~s}$ rest between sets, in order to assess the effects of different rest intervals between sets on Ts/Co ratio. We hypothesized that when using short rest intervals between the sets in resistance exercise to failure (maximum repetitions per sets); the endocrine response should be larger along with a greater metabolic stress (i.e., lactate) than that of long rest periods between the sets. So, the Ts/Co ratio would be lower during RE with short rest period between sets.

\section{Subjects}

Ten experienced resistance-trained college-age males (age, $22 \pm 2$ years; weight, $84 \pm 8 \mathrm{~kg}$; height, $178.5 \pm 8.5$; at least 1 year of RE experience) volunteered for this study. Each subject had at least 1 year recreational experience with resistance training and performed at least three resistance training sessions per week during the previous 6 months, but none were competitive strength athletes. The values for $1 \mathrm{RM}$ were $105.62 \pm 18 \mathrm{~kg}$ for bench press and $106.31 \pm 19.71 \mathrm{~kg}$ for squat. Subjects were informed of the experimental risks and signed an informed consent document prior to the investigation. The study protocol was reviewed and approved by the Ethical Committee at the University of Kurdistan. Subjects were on their ordinary diet, not permitted to use nutritional supplementation and did not consume anabolic 
steroids or any other anabolic agents known to increase performance.

\section{Experimental design}

The subjects were familiarized with the experimental testing procedures during a control day about one week before the actual measurements. Resistance load verification for the experimental bench press and squat exercises were also determined. All of the subjects went through three strength exercise trials of different rest intervals between sets. The strength exercises lasted from 09:00 hours to 11:00 hours and to avoid any potential carry-over effects and threats of internal validity, each of the three protocols was performed in a counterbalance order by all 10 participants. At least $48 \mathrm{~h}$ but not more than $72 \mathrm{~h}$ of recovery time was allowed between each training session. ${ }^{22}$ During the control day, three blood samples were obtained from each subject. One blood sample was drawn in the morning after 12 hours of fasting and approximately eight hours of sleep for determination of basal serum hormone concentration. Two blood samples were also drawn without exercise at the same time of day that each subject would later under tack his heavyresistance loading protocols to determine the normal diurnal variation of serum hormone concentration. During the exercise sessions, blood samples $(5 \mathrm{ml})$ were drawn from an antecubital vein into $10-\mathrm{ml}$ serum Vacutainer tubes at rest (Pre); immediately after (Post) and $30 \mathrm{~min}$ after the end of the session (30Post). The experimental design comprised three resistance exercise protocols involving 4 sets bench press and squat at $85 \%$ of $1 \mathrm{RM}$ to failure with 60 (P60), 90 (P90) and 120 (P120) s rest between sets.,23

\section{Strength testing}

Maximal strength in bench press and squat was assessed by using one repetition maximum (1RM). ${ }^{3,22,29}$ Warm-up consisted of a set of five repetitions at the loads of $40-50 \%$ of the perceived maximum. An attempt was considered successful when the movement was completed through a full range of motion without deviating from proper technique and form. Spotters were present to provide verbal encouragement and safety for the subjects. To ensure that all subjects were moving at approximately the same velocity for each repetition, each set was timed using a handheld stopwatch. The spotter called out a cadence for the eccentric and concentric phases of each repetition. The repetition velocity consisted of a 3-s eccentric phase followed by a 1-s concentric phase. During the next 3 testing sessions, 4 sets of the squat and bench press were performed with a 60-, 90-, or 120-s rest interval between sets. A counterbalance procedure was used to determine the order of the rest interval between sets for each testing session. Subjects didn't allow continuing with their normal workouts throughout the duration of the study. Also, subjects were instructed not to perform training $48 \mathrm{~h}$ before the testing session and subjects were instructed not to change their eating patterns during the study. 3,23

\section{Hormonal analysis}

Blood samples $(5 \mathrm{ml})$ were collected into tubes from the antecubital fossa using standard venipuncture techniques.
Table 1 Testosterone and cortisol levels (mean \pm SD) during pre-exercise (Pre), immediately post (Post), and 30 minutes post (30 min Post) resistance exercise with the 60 second (P60), 90 second (P90), and 120 second (P120) rest between sets

\begin{tabular}{llll}
\hline Rest between sets & Pre & Post & 30 min Post \\
\hline Testosterone $^{\mathrm{a}}(\mathrm{ng} / \mathrm{mL})$ & & & \\
P60 & $4.76 \pm 2.26$ & $4.13 \pm 1.30$ & $5.25 \pm 1.39$ \\
P90 & $5.61 \pm 2.19$ & $6.80 \pm 2.01^{\mathrm{b}}$ & $7.18 \pm 1.59$ \\
P120 & $5.03 \pm 2.21$ & $7.27 \pm 1.93^{\mathrm{b}, \mathrm{c}} 7.78 \pm 1.61^{\mathrm{c}}$ \\
Cortisol $(\mathrm{ng} / \mathrm{mL})^{\mathrm{a}}$ & & & \\
P60 & $133 \pm 18$ & $255 \pm 45^{\mathrm{c}, \mathrm{d}}$ & $239 \pm 48^{\mathrm{c}}$ \\
P90 & $152 \pm 39$ & $248 \pm 51^{\mathrm{c}, \mathrm{d}}$ & $211 \pm 73^{\mathrm{c}}$ \\
P120 & $156 \pm 52$ & $176 \pm 38$ & $243 \pm 111$ \\
\hline
\end{tabular}

a Partial of these results has been published previously $y^{3,23}$.

b Significant difference with P60.

c Significant difference with pre-exercise.

d Significant difference with P120.

Blood samples were centrifuged at $3000 \mathrm{rpm}$ (5000 g) for $10 \mathrm{~min}$ at room temperature. Serum was stored at $-20^{\circ} \mathrm{C}$ until analysis. Serum TS and Co concentrations were determined using enzyme-linked immunosorbent assay (DRG Instruments $\mathrm{GmbH}$, Germany; Division of DRG International, Inc., Hamburg, Germany) and Cortisol (Enzym Immunosorbant Assay, RADIM SpA, Via del Mare, 125- 00040 Pomezia, Roma, Italy), respectively. To eliminate inter-assay variance, all samples for a particular assay thawed once and analyzed in the same assay run. All samples were run in duplicate with a mean inter- and intra-assay coefficients of variances of 9.94 and $4.16 \%$ for serum TS and $6.9 \%$ and $6.2 \%$ for serum cortisol.

\section{Statistical analyses}

Data are expressed as mean \pm SD. Statistical evaluation was performed with SPSS 16.0 for windows and two-way $(3 \times 3)$ repeated measures ANOVA (rest intervals $\times$ time [Pre, Post, 30 min Post]) were used to compare blood samples for the different programs. Multiple comparisons with confidence interval adjustment by the Bonferroni method were used as post hoc when necessary. Statistical analysis compared the blood samples for each sequence against resting. The significance level was set at $p<0.05$.

\section{Results}

Testosterone and cortisol levels (mean \pm SD) during Pre, Post, and 30Post resistance exercise with 60, 90, and $120 \mathrm{~s}$ rest between sets are depicted in table 1 . The Ts/Co ratio to the RE protocols can be seen in Figure 1. Comparison within protocols revealed that during $\mathrm{P} 60$, Ts/Co ratio was significantly lower at post and $30 \mathrm{~min}$ post when compared with Pre-exercise $(p<0.05)$. The Ts/Co ratio comparison between protocols (P60, P90, and P120) revealed that Ts/Co ratio at post exercise was significantly higher for P120 than P60 and P90 ( $p<0.05)$, but no difference was found between P60 and P90 $(p>0.05)$. 


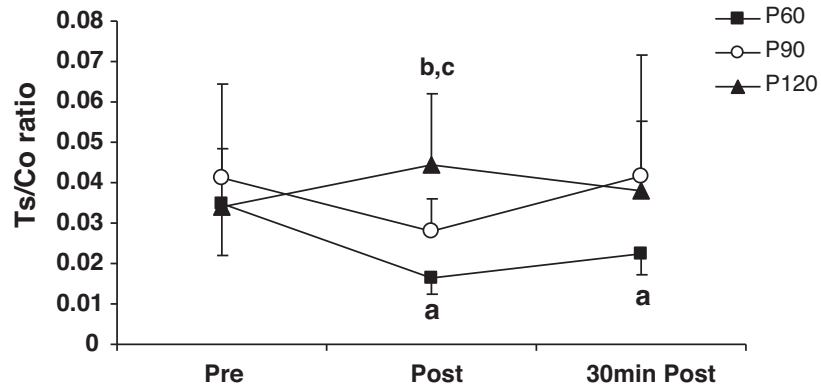

Figure 1 Testosterone to Cortisol ratio (Ts/Co ratio) (mean $\pm \mathrm{SD}$ ) during pre-exercise (Pre), immediately post (Post), and 30 minutes post ( $30 \mathrm{~min}$ Post) resistance exercise with the 60-second (P60), 90-second (P90), and 120-second (P120) rest periods between sets. ${ }^{a}$ Significant difference with pre-exercise $(p<0.05)$. ${ }^{b}$ Significant difference with P60. ${ }^{c}$ Significant difference with P90.

\section{Discussion}

Resistance exercise is the most effective way for achieving an acute increase in the concentration of anabolic hormones, which in turn stimulates strength and muscle hypertrophy. ${ }^{4,22}$ High-intensity hypertrophic RE when performed in multiple sets (3-5 sets for each exercise), with short rest intervals (60-120 s) and high repetition (8-12 repetition) lead to acute hormonal responses. ${ }^{24-26}$ The amount or time of acute hormonal responses after RE, may be related to gaining of muscle strength and hypertrophy. ${ }^{2,27}$ The role of acute hormonal responses is very important because anabolic hormones such as testosterone will increase protein synthesis in muscle cells. ${ }^{28}$

Rest interval between sets in RE has a special important which is defined as the time period between the ends of training set and commence of the next set so that body condition of the individual approached to the physiological stance before the activity. Amount of rest between sets affects the metabolism, cardiovascular function, hormonal response, also number of repetition in subsequent sets. $^{1,4,22,29,30}$

The aim of our study was to compare the influence of rest interval periods on the Ts/Co ratio in resistance trained men. This ratio ( $\mathrm{Ts} / \mathrm{Co}$ ) has been commonly used as investigative of adaptation and/or stress index. Our data demonstrated that 120 s rest interval caused significant increases in testosterone compared to Co immediately after RE. The Ts/Co ratio was significantly higher immediately after resistance exercise in P120 trail compared to P60, and P90 trails. However, it wasn't significantly different between trails at $30 \mathrm{~min}$ after exercise. Whereas, Ts/Co ratio in P60 trail decreased significantly after resistance exercise and remained lower until $30 \mathrm{~min}$ after exercise but did not exhibit in P90 and P120 trails.

These results indicating that the metabolic condition induced by RE with $120 \mathrm{~s}$ rest interval between sets is favorable to the protein anabolism. ${ }^{8,9}$ Immediately (but, no longer) after resistance exercise, the participants presented a significant increase in this relation, fact that may be explained mainly by the more increasing in the testosterone than cortisol concentration. Herein, testosterone level increased significantly in post exercise than baseline by $120 \mathrm{~s}$ rest intervals and remained at higher level after 30 min recovery. But it didn't change significantly neither in P60 nor P90 after exercise. On the other hand, our data revealed that cortisol level after short rest interval (both, 60 and $90 \mathrm{~s}$ ) increased after resistance exercise but not by $120 \mathrm{~s}$. These findings are in accordance with those of Kraemer et al, ${ }^{17,26}$ who showed that high intensity RE (5RM) with large muscle groups and with 3-min rest between sets elevates TS concentrations.

Furthermore, Cortisol secretion responds quite rapidly to various stresses (e.g. exercise, hypoglycemia, surgery, etc.), typically within minutes. The importance of the Co response to RE is related to its catabolic effects on skeletal muscle. As a result, Co has been the catabolic hormone most frequently analyzed after RE. ${ }^{25}$ Gotshalk et $\mathrm{al}^{31}$ reported that three sets versus one set of resistance exercises resulted in a greater cortisol increase. In the present study rest intervals between sets affect serum Co concentrations and observed higher level of Co concentrations in RE with short rest intervals $(60-90 \mathrm{~s})$ between sets than long rest interval which is in accordance to previous studies. ${ }^{21,25}$ They have demonstrated that shorter rest intervals are associated with an increased Co response after resistance training. However, contrary to our findings, Bottaro et $\mathrm{al}^{15}$ reported that Co concentrations were not different among three RE protocol with 30,60 and 120 s rest durations between sets. The mechanisms responsible to increase Co concentrations in RE maybe due to physiological and psychological stress. ${ }^{32}$ Thus, higher levels of blood Co during RE with 60 and 90 s rest periods as compared to $120 \mathrm{~s}$ protocol, maybe due to an increase in physiological stress in response to a short rest interval.

Our data revealed that short rest interval (P60) caused a significant reduction in $\mathrm{Ts} / \mathrm{Co}$ ratio after resistance exercises so that, its values at immediately and 30 min post exercise were significantly lower than the baseline. This is due to an exercise-induced increase in cortisol concentration that is more than testosterone concentration in P60 trail. Viru and Viru $^{5}$ emphasize that this change is clearly an overreaching indicative, but not an overtraining indicative. The reduction on the post-training Ts/Co ratio emphasized in $\mathrm{P} 60$, suggests that this stimulus has represented a punctual intense overload to the organism.

There are few limitations of this study that warrant discussion. First, hormonal samples didn't adjust for hemoconcentration changes which likely occurred to some degree as a results of RE. Therefore, it is recommended that future studies evaluate the plasma change in order to adjust hormonal concentrations. Second, these findings are specific to the RE protocol that was performed to failure. Further investigations are necessary to determine if these findings are generalizable to the RE protocol not to failure.

\section{Practical applications}

In summary, the present data indicate that RE with short rest period (60 and $90 \mathrm{~s}$ ) induced increase in serum cortisol concentration more than testosterone result in low Ts/Co ratio that it suggests catabolic processes are prevailed. In contrast, long rest period (120 s) between sets in resistance exercise results in higher Ts/Co ratio due to more increased 
testosterone level than cortisol after exercise. It may be because of higher training volume and lower physiological stress in RE with 120 s rest between sets vs. lower volume and higher stress with 60 and 90 s rest periods between sets. Therefore, it is recommended that long rest periods between RE sets' can be used to produce anabolic milieu in order to gain muscle mass and strength.

\section{Conflicts of interest}

The authors have no conflicts of interest to declare.

\section{References}

1. Kraemer WJ, Noble BJ, Clark MJ, Culver BW. Physiologic responses to heavy resistance exercise with very short rest periods. Int J Sports Med. 1987;8:247-52.

2. Kraemer WJ. Endocrine responses and adaptations to strength training. In: Komi PV, editor. Strength and Power in Sport. Oxford; Boston: Blackwell Scientific Publications; 1992. p. 191-304.

3. Rahimi R, Qaderi M, Faraji H, Boroujerdi SS. Effects of very short rest periods on hormonal responses to resistance exercise in men. J Strength Cond Res. 2010;24:1851-9.

4. Spiering BA, Kraemer WJ, Anderson JM, Armstrong LE, Nindl BC, Volek JS, et al. Resistance exercise biology, manipulation of resistance exercise program variables determines the responses of cellular and molecular signaling pathways. Sports Med. 2008;38:527-40.

5. Viru A, Viru M. Assessing changes in adaptivity for optimizing training strategies. In: Viru A, Viru M, editors. Biochemical monitoring of sport training. Champaign: Human Kinetics; 2001. p. 193-220.

6. Uchida MC, Bacurau RFP, Navarro F, Pontes Jr FL, Tessuti VD, Moreau RL, et al. Alteration of testosterone: cortisol ratio induced by resistance training in women. Rev Bras Med Esporte. 2004;10:169-72.

7. Volek JS, Kraemer WJ, Bush JA, Incledon T, Boetes M. Testosterone and cortisol in relationship to dietary nutrients and resistance exercise. J Appl Physiol. 1997;82:49-54.

8. Keizer HA. Neuroendocrine aspects of overtraining. In: Kreider RB, Fry AC, O'Toole ML, editors. Overtraining in sport. Champaign: Human Kinetics; 1998. p. 145-67.

9. Urhausen A, Gabriel H, Kinderman W. Blood hormones as markers of training stress and overtraining. Sports Med. 1995;20:351-76.

10. Fry AC, Kraemer WJ, Stone MH, Warren BJ, Fleck SJ, Kearney JT, et al. Endocrine responses to overreaching before and after 1 year of weightlifting. Can J Appl Physiol. 1994;19:400-10.

11. Kraemer WJ. Endocrine responses to resistance exercise. Med Sci Sports Exer. 1988;20 Suppl 5:S152-157.

12. Humberto M, Simão R, Moreira LM, de Souza RA, de Souza JAA, de Salles BF, et al. Effect of rest interval length on the volume completed during upper body resistance exercise. J Sports Sci Med. 2009;8:388-92.

13. Kraemer WJ. A series of studies? The physiological basis for strength training in American football: Fact over philosophy. J Strength Cond Res. 1997;11:131-42.

14. Ratamess RA, Falvo MJ, Mangine GT, Hoffman JR, Faigenbaum $A D$, Kang $J$. The effect of rest interval length on metabolic responses to the bench press exercise. Eur J Appl Physiol. 2007;100:1-17.

15. Bottaro M, Martins B, Gentil P, Wagner D. Effects of rest duration between sets of resistance training on acute hor- monal responses in trained women. J Sci Med Sport. 2009;12: 73-8.

16. Buresh R, Berg K, French J. The effect of resistive exercise rest interval on hormonal response, strength, and hypertrophy with training. J Strength Cond Res. 2009;23:62-71.

17. Kraemer WJ, Marchitelli LJ, Gordon SE, Harman E, Dziados JE, Mello R, et al. Hormonal and growth factor responses to heavyresistance exercise protocols. J Appl Physiol. 1990;69:1442-50.

18. Gentil P, Bottaro M, Oliveira E, Veloso J, Amorim N, Saiuri A, et al. Chronic effects of different between-set rest durations on muscle strength in nonresistance trained young men. J Strength Cond Res. 2010;24:37-42.

19. Pincivero MD, Lephart SM, Karunakara RG. Effects of rest interval on isokinetic strength and functional performance after short term high intensity training. $\mathrm{Br} \mathrm{J}$ Sports Med. 1997;31:229-34.

20. Robinson JM, Stone MH, Johnson RL, Penland CM, Warren BJ, Lewis RD. Effects of different weight training exercise/rest intervals on strength, power, and high intensity exercise endurance. J Strength Cond Res. 1995;9:216-21.

21. Ahtiainen JP, Pakarinen A, Alen M, Kraemer WJ, Häkkinen K. Short vs. long rest period between the sets in hypertrophic resistance training: influence on muscle strength, size, and hormonal adaptations in trained men. J Strength Cond Res. 2005; 19:572-82.

22. Boroujerdi SS, Rahimi R. Acute GH and IGF-I responses to short vs. long rest period between sets during forced repetitions resistance training system. South African J Res Sport, Phy Ed Rec. 2008;30:31-8.

23. Rahimi R, Ghaderi M, Mirzaei B, Faraji H. Acute IGF-1, cortisol and creatine kinase responses to very short rest intervals between sets during resistance exercise to failure in men. World Appl Sci J. 2010;8:1287-93.

24. Hakkinen K, Pakarinen A. Acute hormonal responses to two different fatiguing heavy resistance exercise protocols in male strength athletes. J Appl Physiol. 1993;74:882-7.

25. Kraemer WJ, Fleck SJ, Dziados JE, Harman EA, Marchitelli LJ, Gordon SE, et al. Changes in hormonal concentrations after different heavy resistance exercise protocols in women. J Appl Physiol. 1993;75:594-604.

26. Kraemer WJ, Gopdon SE, Fleck SJ, Marchitelli LJ, Mello R, Dziados JE, et al. Endogenous anabolic hormonal and growth factor responses to heavy-resistance exercise males and females. Int J Sports Med. 1991;12:228-35.

27. Ahtiainen JP, Pakarinen A, Alen M, Kraemer WJ, Häkkinen K. Acute hormonal and neuromuscular responses and recovery to forced vs. maximum repetitions multiple resistance exercises. Int J Sports Med. 2003;24:410-8.

28. Ferrando AA, Tipton KD, Dolye D, Phillips SM, Cortiella J, Wolfe RR. Testosterone injection stimulates net protein synthesis but not tissue amion acid transport. Am J Physiol. 1998;275:E2864-71.

29. Rahimi R. Effect of different rest intervals on the exercise volume completed during squat bouts. J Sports Sci Med. 2005; 4:361-6.

30. Rahimi R, Boroujerdi SS, Ghaeeni S, Noori SR. The effect of different rest intervals between sets on the training volume of male athletes. Facta Univ Phys Educ Sport. 2007;5: 37-46.

31. Gotshalk LA, Loebel CC, Nindl BC, Putukian $M$, Sebastianelli WJ, Newton RU, et al. Hormonal responses of multiset versus single-set heavy resistance exercise protocols. Canadian J Appl Physiol. 1997;22:244-55.

32. Mulligan SE, Fleck SJ, Gordon SE, Koziris LP, Triplett-McBride NT, Kraemer WJ. Influence of resistance exercise volume on serum $\mathrm{GH}$ and cortisol concentrations in women. J Strength Cond Res. 1996;10:256-62. 